\section{UCB Library to preserve ag literature}

An $\$ 850,000$ grant from the National

Endowment for the Humanities is helping the

UC Berkeley library identify and preserve

historical literature about agricultural development and rural life.

Norma Kobzina, librarian at the

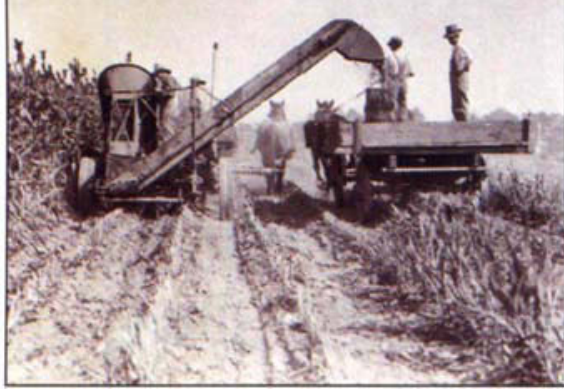

UC Bioscience and Natural Resources Library, is heading the venture at Berkeley. Kobzina says that California holds a vast wealth of information important to this project, which is a cooperative effort with eight other land-grant university libraries.

The rich literature to be preserved traces agriculture's evolution from a home-and-family way of life to the business enterprise of today. Much of the literature is from the original College of Agriculture (now UC Berkeley's College of Natural Resources) established in 1868. The college has myriad primary research resources and published documents, including the diaries and letters of settlers.

Many California land-grant publications have been preserved through a previous micro- filming project. With this project, the UC Berkeley library staff will improve access to approximately 900 titles in more than 2,160 volumes, the most important $17 \%$ of materials still in need of preservation.

The project is part of the National Agricultural Preservation Program for Agricultural Literature developed by the National Agricultural Library and the US Agricultural Information Network in 1993. The initial work has been funded for the first year, beginning in July 1996, to identify state-level literature documenting the history of agricultural development and rural life covering 1820-1945. Four of the nine land-grant libraries will preserve the most valuable titles; UC is among the other five that will identify and rank the titles, but not preserve volumes until additional funding is received.

All historical literature will be identified and evaluated by a panel of scholars. Kenneth Carpenter, professor emeritus, and Garrison Sposito, professor, will represent UC Berkeley. Ann Foley Scheuring, who has done extensive writing about California agriculture, and Morton Rothstein, professor at UC Davis, are also on the panel.

\title{
Letter
}

\section{Dear Editor:}

"Growers Prefer Personal Delivery of UC Information," an article appearing in the MayJune issue, overlooked the significant contributions of pesticide consultants.

The California Agricultural Production Consultants Association (CAPCA) would like to stress the need and importance of the role of the licensed pest control adviser (PCA) in this state's production of safe and abundant food, fiber and flowers. CAPCA believes that California growers and producers are able to have a variety and selection of many resources to assist in their decision-making process. CAPCA members have always stressed the need to work cooperatively with the local and state farm advisor and cooperative extension staff.

The article should have pointed out the unique working relationship that the California growers and pest management industry have; in fact, the PCA and the farm advisors are interdependent resources to the grower community. Without the success of the farm advisors, the PCAs could not achieve their educational development. Likewise, the field practices and trials performed daily by PCAs lend to the successful research and development by the farm advisors.

Kimberly A. Crum, Executive Director Karen Watts, President

The California Agricultural Production Consultants Association (CAPCA) represents 3,600 of the 4,800 licensed pest control advisers (PCAs) that provide pest management consultation for agricultural industries of this state. 